\section{Dr. Saif Afat erhält den Marc-Dünzl-Preis 2019}

Auf der 54. Jahrestagung der Gesellschaft für Neuroradiologie („neuroRAD“) wurde Dr. Saif Afat vom Universitätsklinikum Tübingen mit dem Marc-Dünzl-Preis ausgezeichnet. Er ist aktuell Sprecher des „Forscher für die Zukunft“-Programms der Deutschen Röntgengesellschaft (FFZ) und Vorstandsmitglied des Forums Junge Radiologie. Der Preis wurde ihm für seine Arbeit „Diagnostic Accuracy of Simulated LowDose Perfusion CT to Detect Cerebral Perfusion Impairment after Aneurysmal Subarachnoid Hemorrhage: A Retrospective Analysis“ verliehen.

\section{Hintergrund}

Dieser Preis geht auf ein tragisches Ereignis zurück, bei dem ein junger Neuroradiologe, der in München in der Abteilung von Prof. Brückmann arbeitete, tödlich verunglückte. In der Bewältigung dieses furchtbaren Schicksalsschlags und um das Andenken an den Sohn zu erhalten, gründeten die in USA lebenden Eltern dort einen Fonds mit dem Namen des Sohnes und sammelten zunächst 37000 USD. Durch den Kontakt mit Prof. Brückmann entstand dann die Idee, einen Gedächtnispreis in Deutschland auszuschreiben und diesen von der DGNR vergeben zu lassen.

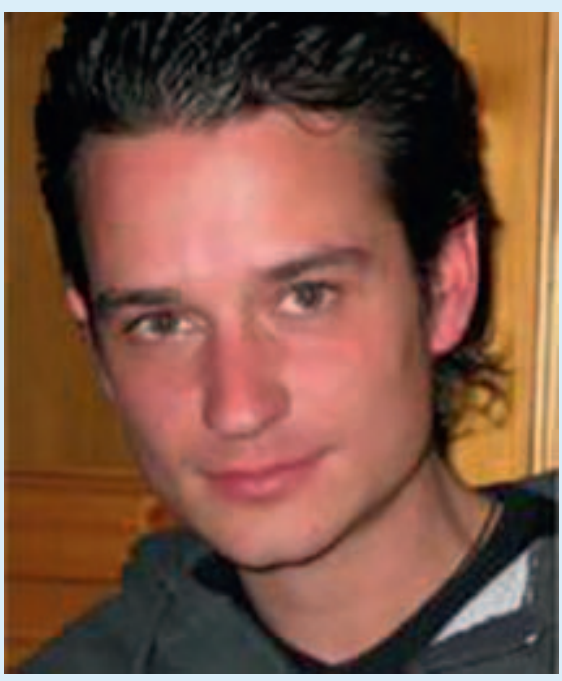

Marc Dünzl

\section{Aus der Ausschreibung}

Die Deutsche Gesellschaft für Neuroradiologie schreibt zum Gedenken an Herrn Marc Dünzl und zur Förderung des jungen wissenschaftlichen Nachwuchses in unserem Fach den Marc-Dünzl-Preis für eine klinisch-neuroradiologische und/oder experimentelle Arbeit aus, die bereits publiziert oder zur Publikation eingereicht ist.

Der Preis ist mit $2500 €$ dotiert und soll zur Unterstützung der weiteren wissenschaftlichen Arbeit verwendet werden. Der Preis wird anlässlich der Jahrestagung der Deut-

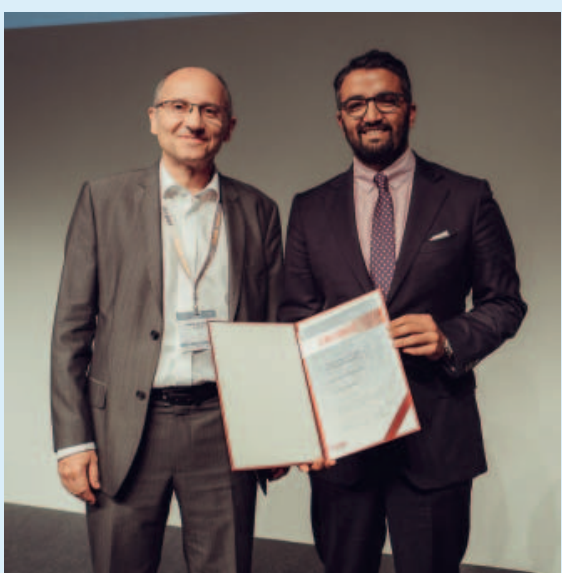

Dr. Saif Afat (re.) mit Prof. Dr. Martin Wiesmann bei der Preisverleihung auf dem neuroRAD 2019. Foto: DGNR

schen Gesellschaft für Neuroradiologie verliehen. Bewerber/innen sollten Mitglied der DGNR und bei Ablauf der Bewerbungsfrist nicht älter als 32 Jahre sein. Der Gewinner wird spätestens zwei Wochen vor der Jahrestagung über die Entscheidung des Komitees benachrichtigt und soll die Ergebnisse der Arbeit bei der Preisverleihung in einer 10-minütigen Zusammenfassung vorstellen. Die Arbeit kann in englischer oder deutscher Sprache verfasst sein und sollte noch nicht ausgezeichnet oder an anderer Stelle zur Prämierung eingereicht sein. 